PLPB: Pendidikan Lingkungan dan Pembangunan Berkelanjutan

DOI: https://doi.org/10.21009/PLPB.162.04

DOI: 10.21009/PLPB

\title{
DEVELOPMENT OF TEACHING MATERIALS ESD (EDUCATION FOR SUSTAINABLE DEVELOPMENT) IN COACHING SKILLS OF SELF CHILDREN WITH INTELLECTUAL CHALLENGES IN SMA LB C IN JAKARTA
}

\author{
Nadiroh, Orchid Id: 000.0001-9807-2536, \\ SintaID: 6003834, nadiroh@unj.ac.id \\ Faculty of Social \\ and \\ Irah Kasirah Faculty of Education, State University of Jakarta \\ irahkasirah@yahoo.co.id,irahkasirah66@gmail.com
}

\begin{abstract}
The purpose of this research is to develop teaching materials ESD (Education for Sustainable Development) in subjects Self Development skills in a special program of vocational skills such as making skills of the rest of the patchwork mat and look for alternative learning model development Self Development skills required of teachers in accordance with the child's ability mentally retarded that still form an outline of the learning program.The research was conducted in SLB C East Jakarta. The subjects of research that high school teachers and students mentally retarded LB C. Outcome or product part of this research is the study of ESD (Education for Sustainable Development) in subjects Self Development skills in a special program of vocational skills makedoormats from the rest of the patchwork.The results of this study are expected to contribute to the implementation of innovative teaching model for teachers SLB C through the development of teaching materials ESD (Education for Sustainable Development) in practice the skillsself help Mentally Retarded Children in order to achieve self-reliance to improve the quality of life of chldren with intellectual challenges.
\end{abstract}

Keywords: ESD (Education for Sustainable Development), Self Development Skills, Skills Make mat from the rest of patchwork, Mentally Retarded Children.

\begin{tabular}{|l|l|l|l|}
\hline Volume XVI & Nomor 02 & September 2015 & ISSN 1411-1829 \\
\hline
\end{tabular}




\section{Pendahuluan}

Berdasarkan hasil riset menunjukan bahwa salah satu faktor yang menyebabkan kualitas hidup anak tunagrahita dalam hal ini sumber daya atau kemampuan kelangsungan hiduptidak meningkat selain faktor keterbatasan intelektual juga faktor pelayanan pendidikan yang dilakukan tidak sesuai dengan kebutuhan. Pembelajaran keterampilan bina diri program khusus keterampilan vokasional dapat menjadi salah satu solusi agar siswa tunagrahita dapat meningkatkan kualitas hidup melalui keterampilan khusus yang dikuasainya agar mereka berdaya secara ekonomi. Kebutuhan perangkat pembelajaran dalam mata pelajaran keterampilan bina diri program khusus keterampilan vokasional dan pemanfaatan bahan/peralatan yang masih layak pakai belum optimal maka diperlukan pengembangan perangkat pembelajaran bermakna untuk memudahkan guru melakukan penilaian dalam mencapai indikator keberhasilan yaitu pendidikan bagi siswa tunagrahita dalam mendukung pembangunan berkelanjutan.

ESD pertama kali dicetuskan oleh Hans J. A. Van Ginkel, mantan rektorUnited

Nations (UN) University dan Staf Ahli Sekjen UN. EfSD istilah aslinya adalah Education Sustainable Development atau di singkat ESD minus for. Mengapa di Indonesia ditambah dengan for?For artinya untuk kata untuk berarti menghasilkan sesuatu, ada tujuan yang ingin dicapai. Untuk menghasilkan sesuatu atau mencapai tujuan, harus ada tindakan (action).

Sedangkan

development

diterjemahkan pengembangan bukan pembangunan, karena pembangunan sering dimaknai pembangunan fisik atau infrastruktur. Pengembangan berkelanjutan (sustainable development) adalah sebuah perubahan, perkembangan atau pengembangan meliputi kehidupan sosial, budaya, ekonomi dan lingkungan secara simultan, berkesinambungan sehingga menghasilkan kondisi tentram, aman, nyaman baik dimasa sekarang maupunyang akan datang. Pengembangan berkelanjutan diartikan sebagai pengembangan yang memenuhi kebutuhan masa kini tanpa menghilangkan kemampuan generasi mendatang untuk memenuhi kebutuhan mereka sendiri.

Definisi ESD menurut UNESCO adalah "proses belajar (atau pendekatan pengajaran) berdasarkan cita-cita dan prinsip-prinsip yang mendasari keberlanjutan dan berkaitan dengan semua tingkat dan jenis pembelajaran untuk menyediakan pendidikan yang berkualitas dan mendorong pembangunan manusia yang berkelanjutan - belajar mengetahui, belajar menjadi, belajar untuk hidup bersama, belajar untuk melakukan dan belajar untuk mengubah diri sendiri dan masyarakat. "

Menurut Wallin dan Harbor self help skill adalah keterampilan Bina Diri merupakan keterampilan yang diperuntukkan untk mencapai atau mendapatkan kemandirian dalam banyak spek kehidupan. Mengajarkan kemampuan ini akan membantu anak agar tidak tergantung kepada orang yang ada di lingkungannya dalam kehidupan sehari-hari. Jadi, keterampilan bina diri bertujuan agar anak menjadi mandiri tidak menjadi beban orang lain yang ada di sekitar anak. Pengertian Pendidikan vokasional merupakan penggabungan antara teori dan praktik secara seimbang dengan orientasi pada kesiapan kerja lulusannya.Kurikulum dalam pendidikan vokasional, terkonsentrasi pada sistem 
pembelajaran keahlian (apprenticeship of learning) pada kejuruan-kejuruan khusus (specific trades).Pendidikan keterampilan merupakan kemampuan khusus yang diselenggarakan agar anak didik memiliki keahlian yang berguna bagi dirinya sendiri sebagai bekal hidupnya di masyarakat.

Menurut AAMD ( The American On Mental Deficiency ), yang dikutip oleh Muljono \& Sudjadi, gangguan intelektual adalah gangguan mental yang mengacu pada fungsi intelektual umum yang nyata dibawah rata-rata, bersamaan dengan kekurangan dalam adaptasi tingkah laku dan berlangsung dalam masa perkembangan. Jadi anak tunagrahita adalah anak yang mempunyai gangguan mental pada fungsi intelektual umum di bawah rata-rata anak normal, kekurangan dalam beradaptasi dengan lingkungannya, dan berlangsung dalam masa perkembangan.

Dalam penelitian ini Bahan ajar ESDmerupakan bahan ajar yang disiapkan dengan cara mengintegrasikan konsep-konsep dan alat-alat analisis dari berbagai disiplin ilmu untuk membantu guru keterampilan SMA LB C dan siswa tunagrahita lebih memahami pembelajaran keterampilan vokasional membuat keset yang bernilai guna untuk mencapai pembangunan pendidikan berkelanjutan.

\section{Metodologi Penelitian}

Tujuan penelitian ini yaitu mengembangkan bahan ajar ESD (Education for Sustainable Development) dalam melatih keterampilan Bina Diri pada program khusus keterampilan vokasional membuat keset dari limbah kain perca bagi siswa tunagrahita Sekolah Menengah Atas Luar Biasa bagian C di Jakarta Timur.
Penelitian ini dilaksanakan di Sekolah Menengah Atas Luar Biasa Tunagrahita SMA LB- C Jakarta Timur.Penelitian dilakukan pada Januari 2014- November 2014.

Metode dan tahapan penelitian yaitu meliputi: 1) Studi literatur; 2) Studi lapangan tentang bentuk pembelajaran vokasional di SMA LB C saat ini ; 3) Deskriptif dan analisis temuan; 4) Temuan draft Desain Model Pembelajaran Educational for Sustainable Development: 5) Penyusunan perangkat model pembelajaran Educational for Sustainable Development; 6) Uji terbatas dengan tahapan uji ahli desain instruksional, uji ahli materi ketunagrahitaan dan ahli bahas; uji one to one terhadap3 orang guru keterampilan SMA LB C; uji kelompok kecil terhadap 9 orang guru keterampilan di SMA LB C Jakarta Timur.

\section{Hasil Penelitian Dan Pembahasan}

Berdasarkan hasil penelitian pendahuluan yang dilakukan kepada guru Sekolah Luar Biasa yang mengajar siswa tunagrahita pada jenjang sekolah menengah atas, diperoleh hasil sebagai berikut: 1) guru belum memahami tentang Education for Sustainable Development/ESD atau Pendidikan Pembangunan Berkelanjutan) 2) guru belum memahami karakteristik anak tunagrahita, sehingga dalam proses pembelajaran di kelas guru masih menganggap kemampuan siswa sama; 3) guru belum membuat silabus mata pelajaran bina diri; 4) guru belum membuat silabus pembelajaran keterampilan membuat keset bagi termasuk siswa tunagrahita sehingga tidak berkembang secara optimal; 5) guru yang sudah mengajar keterampilan

\begin{tabular}{|l|l|l|l|}
\hline Volume XVI & Nomor 02 & September 2015 & ISSN 1411-1829
\end{tabular}


membuat keset pada siswa tunagrahita belum menggunakan media yang efektif. Melalui hasil penelitian pendahuluan maka dapat dianalisis kebutuhan dalam pengembangan bahan ajar ESD (Education for Sustainable Development)/ Pendidikan Pembangunan Berkelanjutan pada pembelajaran bina diri dalam keterampilan membuat keset bagi siswa tunagrahita di sekolah luar biasa yaitu :1) diperlukannya kompetensi guru dalam memahami konsep ESD/Education for Sustainable Development (Pendidikan Pembangunan Berkelanjutan) siswa tunagrahita di SLB Bagian C; 2) diperlukannyasilabus dan Rencana Program Pembelajaran mata pelajaran keterampilan bina diri vokasional keterampilan membuat keset yang diperuntukkan SMA di SLB C; 4) dibutuhkan bentuk bahan ajar ESD, bahan ajar yang dibutuhkan berisikan tentang materi lingkungan yang berkaitan dengan materi pembelajaran keterampilan membuat keset pada siswa tunagrahita di SMALB Bagian C.

\section{MODEL BAHAN AJAR}

Model bahan ajar ESD ini merupakan hasil daripengembangan Silabus dan Rencana Program Pembelajaran. Buku Teks Pendidikan Pembangunan Berkelanjutan ini untuk siswa Tunagrahita di Sekolah Menengah Atas Luar Biasa.

\section{a. Model Konseptual}

Model konseptual merupakan perwujudan dari konseptualisasi teoriteoridan prinsip-prinsip yang terintegrasi sedemikian rupa membentuk buku teks pendidikan pembangunan berkelanjutan untuk siswa tunagrahita di Sekolah Menengah Luar Biasa pada mata pelajaran keterampilan vokasional membuat keset. Berangkat dari konsep- tualisasi variabel-variabel lingkungan belajar yang merupakan latar pembelajaran keterampilan membuat keset bagi siswa tunagrahita. Kemudian konseptualisasivariabel-variabel pembelajaran keterampilan vokasional membuat keset di SMA LB C merupakan definisi dari apa yang perlu diamati.

\section{b. Model Prosedural}

Model ini merupakan perwujudan tahapan-tahapan penyusunan buku teks pendidikan pembangunan berkelanjutan dengan dimodifikasi mengikuti langkahlangkah :

Tahap identifikasi kebutuhan pembelajaran dimulai dengan merujukkepada kompetensi pedagogik guru keterampilan, di antaranya yang sangat terkait dengan pengembangan model bahan ajar ESD yaitu kompetensi dalam menguasai karakteristik siswa, menguasai teori belajar dan prinsipprinsip pembelajaran keterampilan membuat keset, mengembangkan kurikulum yang terkait dengan bidang pengembangan yang diajarkan, membuat penilaian dan evaluasi proses dan hasilbelajar, memanfaatkan hasil penilaian dan evaluasi untuk kepentingan pembelajaran. Jadi pengembangan bahan ajar ESD ini bertujuan untuk menghasilkan guru keterampilan yang berkompeten dalam menerapkan teori belajar dan prinsip-prinsip pembelajaran keterampilan membuat keset bagi siswa, mampu mengembangkan kurikulum ESD yang sesuai dengan kebutuhan siswa tunagrahita, dan menyelenggarakan penilaian dan evaluasi proses dan hasil belajar sesuai dengan kemampuan siswa tunagrahita. Berdasarkan hasil penelitian pendahuluan yang dilakukan diperoleh gambaran sebagai berikut:

a. Terkait dengan pemahaman guru terhadap karakteristik siswa, semua guru 
keterampilan sudah mampu mengenali karakterisitik siswa tunagrahita dengan baik.

b. Terkait dengan penguasaan konsep ESD pada pembelajaran keterampilan, semua guru sudah mengetahu ipembelajaran keterampilan membuat keset, namun dalam pengaplikasiannya guru langsung pada praktek pembuatan keset, dan khusus untukprinsip-prinsip pembelajaran ESD bagi siswa tunagrahita guru belum mengetahui dan mengerti caranya, hal ini berdampak pada cara gurumengajar siswa tunagrahita seperti pada mata pelajaran praktek lainnya tanpa memahami asal usul kebutuhan adanya pembuatan keset.

c. Dalam mata pelajaran keterampilan, guru hanya membuat silabus dan beberapa guru tidak membuat Rencana Program Pembelajaran sehingga guru hanya berdasarkan kreativitas masingmasing karena tidak adanya buku ajar atau bahan ajar pada mata pelajaran keterampilan khususnya pembelajaran keterampilan membuat keset.

d.Dalam membuat penilaian dan evaluasi proses dan hasil belajar untuk siswa tunagrahita guru mengaplikasikannya melalui penilaian kognitif saja sedangkan pengukuran kemampuan membuat keset siswa melalui tahapan bimbingan guru saja.

f. Untuk memanfaatkan hasil penilaian dan evaluasi untuk kepentinganpembelajaran dan ketuntasan belajar, semua guru hanyaberlandaskan pada KKM (Kriteria Ketuntasan Minimal) tidak adaindikator lain yang dijadikan acuan dalam menilai ketuntasan belajarsiswa.

Berdasarkan hasil yang diperoleh dalam penelitian pendahuluan terlihat guru belum memiliki kompetensi pedagogik untuk melakukan pembelajaran ESD dalam keterampilan membuat keset terkait dengan pembelajaran bagi siswa tunagrahita. Atas dasar hal tersebut diasumsikan bahwa dibutuhkan modul bahan ajar ESD dalam mata pelajaran keterampilan khususnya keterampilan membuat keset yang di desain dengan langkah-langkah pembuatan keset melalui gambar-gambar yang sesuai agar mudah dipahami dan dapat dipraktikkan oleh guru dalam melakukan pembelajaran keterampilan membuat keset dengan menggunakan prinsip pembelajaran ESD. Diharapkan melalui bahan ajar ini kesenjangan pengetahuanguru tentang Pendidikan Pembangunan Berkelanjutan dapat diatasi dan mampu memecahkan masalah yang dibutuhkan guru dan siswa karena melalui bahan ajar ESD ini pembelajaran ketrampilan vokasional khususnya pembelajaran keterampilan membuat keset dapat dilaksanakan dengan menerapkan pengintegrasian multi disiplin ilmu melalui mata pelajaran lain sehingga siswa tunagrahita lebih mudah mempelajari dan memahami secara keseluruhan tentang kebermaknaan pelaksanaan pembelajaran keterampilan membuat keset. Bahan ajar ESD dikemas dengan menggunakan gambar-gambar menarik yang mendukung pembelajaran dan disesuaikan dengan kebutuhan dan kemampuan siswa tunagrahita yang memilki keterbatasan kemampuan berpikir yang mendukung pembelajaran sehingga diharapkan dapat meningkatkan minat belajar siswa tunagrahita.

Dalam penelitian ini peneliti tidak membuat model baru, namun mengembangkan model yang sudah ada dengan memberikan prinsip pembelajaran ESD melalui kegiatan pembelajaran ESD serta dalam modul yang dikembangkanini lebih diperkaya dengan unsur praktik. Bahan ajar ESD ini dikemas dalam satu paket yang terdiri dari buku teks

\begin{tabular}{|l|l|l|l|}
\hline Volume XVI & Nomor 02 & September 2015 & ISSN 1411-1829 \\
\hline
\end{tabular}


pendidikan pembangunan berkelanjutan / ESD untuk siswa tunagrahita dan buku panduan guru tentang penerapan pembelajaran ESD dalam pembelajaran keterampilan membuat keset dari limbah. Setelah tahap identifikasi kebutuhan pembelajaran yang diperoleh dari hasil penelitian pendahuluan, maka dirumuskan tujuan instruksional umum (TIU) mengacu pada taksonomi Bloom meliputi tujuan pembelajaran yang berkenaan dengan ingatan atau pengetahuan dan pengembangan kemampuan intelektual dan berfikir sesuai dengan keterbatasan berpikir siswa tunagrahita.

\section{c. Model Fisikal/Hipotetik}

Penelitian pengembangan bahan ajar ESD dalam pembelajaran keterampilan vokasional untuk siswa tunagrahita ini bagi guru ini menghasilkan model fisikalhipotetik berupa: 1) silabus dan RPP; 2) bahan ajar ESD berupa buku teks pendidikan pembangunan berkelanjutan.

\section{Kesimpulan}

Berdasarkan hasil analisis di atas maka selanjutnya diputuskan untuk mengembangkan bahan ajar ESD dalam pembelajaran keterampilan membuat keset, yang terdiri dari tiga model yaitu: model konseptual, model prosedural dan model fisikal. Model konseptual merupakan perwujudan dari konseptulisasi teori-teori ESD pada pembelajaran keterampilan siswa tunagrahita yang terintegrasi. Model prosedural merupakan perwujudan tahapan-tahapan dalam penyusunan bahan ajar ESD yang terdiri dari buku teks atau bahan ajar ESD yang terintegrasi sesuai dengan kebutuhan guru dan siswa tunagrahita dalam mata pelajaran keterampilan membuat keset.

\section{Daftar Pustaka}

Borg, Gall, "Educational Research: An Introduction", 1989, dikutip langsung (atau tidak langsung) oleh Nana Syaodih Sukmadinata, Metode PenelitianPendidikan, Bandung: Remaja Rosdakarya, 2009.

Budi Sri Hastuti, Pendidikan Untuk Pengembangan Berkelanjutan dalam Perspektif PNFI, Jurnal PNFI Androgogia, Vol. 1, No. 1, November 2009.

B.R. Hergenhahn, Matthew H. Olson, Theorienof Learning (Teori Belajar), terjemahan Tri Wibowo B.S. (Jakarta: Kencana Prenada Media Group, 2008.

Daniel P. Hallahan, James M.Kaufman, Exceptional Children Introduction to Special Education, $\quad$ Pretice-Hall,Inc: Englewood cliffs, 1991.

Jason M. Wallin, Oak Harbor, Teaching Children With Autisme a Resarce ,N.J. U.S.A. : Merck sharp and Dohme Corp. A Subsidiary of Merk and Co. Inc, 2004.

Maftuchah Yusuf, Pendidikan Kependudukan dan Etika Lingkungan, Yogyakarta: Lembaga Studi dan Inovasi Lingkungan, 2000.

Muljono \& Sudjadi, Pendidikan Luar Biasa Umum 1994, Jakarta: Depdikbud.

\begin{tabular}{|l|l|l|l|}
\hline Volume XVI & Nomor 02 & September 2015 & ISSN 1411-1829 \\
\hline
\end{tabular}


United Nations Decade of Education for Sustainable Development 20052014, Draft International Implementation Scheme, October 2004, UNESCO
Blog UNESCO Bangkok Office. http://prezi.com//lptk-vokasional/ 